\title{
Adolescent Pediatric Kidney Patients Transitioned to Adult Health Care Services through the Philippine General Hospital (PGH) Transition Program (Lipat Kalinga)
}

\author{
Carmelo A. Alfiler, ${ }^{1}$ Emma A. Llanto, ${ }^{2}$ Francisco E. Anacleto, Jr., ${ }^{1}$ Carmencita D. Padilla, ${ }^{3}$ Dolores D. Bonzon, ${ }^{1}$ Elizabeth S. \\ Montemayor ${ }^{4}$ and the UPM-PGH Multidisciplinary Group
}

\begin{abstract}
${ }^{1}$ Section of Pediatric Nephrology, Department of Pediatrics, College of Medicine and Philippine General Hospital, University of the Philippines Manila ${ }^{2}$ Section of Adolescent Medicine, Department of Pediatrics, College of Medicine and Philippine General Hospital, University of the Philippines Manila ${ }^{3}$ Section of Clinical Genetics, Department of Pediatrics, College of Medicine and Philippine General Hospital, University of the Philippines Manila ${ }^{4}$ Section of Adult Nephrology, Department of Internal Medicine, College of Medicine and Philippine General Hospital, University of the Philippines Manila
\end{abstract}

\begin{abstract}
Background. Transitioning from a pediatric clinic to the adult clinic is an important event for patients suffering from chronic illnesses. There are no formal programs in the Philippines for turning over pediatric/adolescent patients to the adult clinics. To date, there is no transitioning program for Filipino children with chronic kidney illness as they move from pediatric to adult health care. A multidisciplinary group at the Philippine General Hospital (PGH) has spearheaded a Transition Program known as Lipat Kalinga for Filipino pediatric chronic kidney disease patients.
\end{abstract}

Objectives. 1) To describe a hospital-based transition model of systematic transfer of adolescents with chronic kidney illnesses from child-centered to adult-oriented services; 2) To describe the socio-demographic and clinical profile of patients enrolled in the program; and 3) To present outcomes of the transfer of adolescent patients to adult heath care units.

Methods. The 2005 Pilot Transition Program was reviewed. The phases of the Transition Program were enhanced prior to its formal launch in 2008. Records of patients seen by the Pediatric Renal Service between June 1, 2008 and June 30, 2011 were reviewed. Patients aged 10-18 years old at last birthday were enrolled in the study. Enrolled patients underwent the four (4) phases of the transition program.

Results. The Transition Program called Lipat Kalinga consists of four phases - preparation, assessment of readiness, physical transfer, and post-transfer follow-up. A total of 51 adolescents aged 10-18 years were enrolled in the study: 17 CKD (Chronic Kidney Disease) and 34 non-CKD patients. Twelve were successfully transferred to Adult Nephrology; 34 were still in the pre-transfer period; and 5 died before transfer.

Corresponding author: Carmelo A. Alfiler, MD

Department of Pediatrics

Philippine General Hospita

University of the Philippines Manila

Taft Avenue, Ermita, Manila 1000 Philippines

Telephone: +632 5240892

Email: caalfilermd@hotmail.com
Conclusion. Lipat Kalinga is a systematic program for transitioning patients with chronic illnesses from the pediatric clinic to the adult clinic. We recommend that Lipat Kalinga be replicated in hospitals with multidisciplinary capabilities. Its supplemental contribution to the holistic care of adolescents afflicted with chronic kidney illnesses at a crucial time of their development is relevant and timely.

Key Words: transition, adolescent, chronic illness, pediatric chronic kidney disease, adult renal

Introduction

Little attention and poor management of children with chronic renal diseases have been observed as they moved from the pediatric to the adult nephrology clinics. ${ }^{1}$ Prof. J. Stewart Cameron from the Renal Unit of the Guy's Hospital, UK emphasized the need for continued care of pediatric patients with renal disease into adult life. ${ }^{2}$ This has prompted two international nephrology associations to release a joint policy statement in 2011, declaring support for a transition process individualized for each young person, focusing on self-management skills as well as assessing support structures and hoping that this consensus would provide a basis for the development of locally-appropriate transition process recommendations. ${ }^{3,4}$ Both the International Society of Nephrology (ISN) and International Pediatric Nephrology Association (IPNA) recognized that the responsibility of effecting a systematic transfer belongs to both pediatric and adult nephrologists.

Survival to age 20 years in children with end-stage renal disease (ESRD) was estimated at $90 \%$ in $1993 .{ }^{5}$ As medical technology and therapeutic management improved over the last two decades, these children have a much greater chance of reaching adulthood. ${ }^{6-10}$ The list of childhood kidney and urinary tract diseases that may persist and must be managed in adult health services includes primary or secondary glomerular, tubulo-interstitial, vasculitic, obstructive and miscellaneous disorders with or without hypertension, and acute kidney injury or chronic renal failure. 
In the Philippines, data from the Pediatric Nephrology Society of the Philippines (Table 1) and the PGH Pediatric Renal Disease Registry (Table 2) show that the above renal and urinary tract syndromes are prevalent and, if protracted, impose a huge medical and psychological burden on the affected child and on his family as the child transitions into adulthood.

Table 1. Pediatric Nephrology Society of the Philippines (PNSP) Data on Renal and Urinary Tract Disorders*

\begin{tabular}{|c|c|c|}
\hline Renal and Urological Disorders & $\begin{array}{c}\text { Number of Patients } \\
\text { from } 1995-2009\end{array}$ & Percentage \\
\hline Primary Nephrotic Syndrome & 5,843 & $27.4 \%$ \\
\hline Acute Post-infectious & 3,917 & $18.4 \%$ \\
\hline \multicolumn{3}{|l|}{ Glomerulonephritis } \\
\hline Acute and Chronic Renal Failure & 3,422 & $16.0 \%$ \\
\hline Complicated and Uncomplicated & 3,100 & $15.0 \%$ \\
\hline \multicolumn{3}{|l|}{ Urinary Tract Infection } \\
\hline Bladder Dysfunction & 1,447 & $6.8 \%$ \\
\hline \multicolumn{3}{|l|}{ [SLE, HSP, etc] } \\
\hline Hypertension and Renal & 939 & $4.4 \%$ \\
\hline \multicolumn{3}{|l|}{ Tubular Disease } \\
\hline IgA Nephropathy & 603 & $2.9 \%$ \\
\hline Congenital or Inherited Disorders & 372 & $1.8 \%$ \\
\hline Tumors & 302 & $1.4 \%$ \\
\hline Urolithiasis & 121 & $0.6 \%$ \\
\hline TOTAL & 21,301 & $100 \%$ \\
\hline \multicolumn{3}{|c|}{ Legend: $S L E=$ systemic lupus erythematosus; HSP = Henoch-Schonlein Purpura } \\
\hline \multicolumn{3}{|c|}{ Source : Anacleto FE. Pediatric Nephrology Society of the Philippines (PNSP) } \\
\hline \multicolumn{3}{|c|}{ Newsletter. Survey of admissions and referrals to four hospitals with post-residency } \\
\hline
\end{tabular}

Table 2. Philippine General Hospital (PGH) Pediatric Renal Registry, 2005 - 2010

\begin{tabular}{lcr}
\hline Renal and Urological Disorders & $\begin{array}{c}\text { Number of Patients } \\
\text { from 1995 - 2009 }\end{array}$ & Percentage \\
\hline Acute Post-infectious & 337 & $25.7 \%$ \\
Glomerulonephritis & 336 & $25.6 \%$ \\
Acute and Chronic Renal Failure & 223 & $17 \%$ \\
Primary Nephrotic Syndrome & 91 & $7 \%$ \\
Hypertension and Renal Tubular & & \\
Disease & 71 & $5.4 \%$ \\
Secondary Glomerulonephritis & & \\
[SLE, HSP, etc] & 66 & $5 \%$ \\
Complicated and Uncomplicated & 62 & $4.7 \%$ \\
Urinary Tract Infection & 60 & $4.6 \%$ \\
Congenital or Inherited Disorders & 41 & $3.1 \%$ \\
Bladder Dysfunction & 16 & $1.4 \%$ \\
Tumors & 7 & $0.5 \%$ \\
IgA Nephropathy & $\mathbf{1 , 3 1 0}$ & $\mathbf{1 0 0 \%}$ \\
Urolithiasis & (Available at & the \\
TOTAL & Rection of
\end{tabular}

Nephrology, Department of Pediatrics, Philippine General Hospital)

A Transition Program from the pediatric renal clinic to the adult renal clinic was piloted in 2005 and officially launched as Lipat Kalinga (Filipino term for "Movement of Care") in 2008. This pioneering program was conducted at the PGH for the following reasons: (1) it is a referral center with a huge patient population, majority of whom belong to socio-economically challenged members of the society; (2) pediatric and adult patients are housed in one complex; (3) subspecialty, multidisciplinary, social and other support services exist and are readily available; in particular, the presence of a strong Adolescent Medicine Section at the Department of Pediatrics; and (4) it has a School for Chronically-ill Children recognized by the Department of Education's Manila City Division that offers mainstream school subjects for hospital inpatients.

The objectives of this paper are: 1) to describe the establishment of a hospital-based transitioning program for chronically-ill kidney patients using the multidisciplinary approach; 2) to describe the socio-demographic and clinical profile of patients in the program; and 3) to discuss the transfer outcomes of adolescent patients to the adult health care unit.

This is a preliminary report of our local experience with Lipat Kalinga. To our knowledge, this is the first report on this subject matter in the Philippines.

\section{Methods}

\section{The PGH Transition Program (Lipat Kalinga)}

The 2005 pilot Transition Program was reviewed. Different phases of the Lipat Kalinga were planned and implemented.

\section{Patients}

Records of patients seen by the Pediatric Renal Service between June 1, 2008 and June 30, 2011 were reviewed. Patients aged 10-18 years old at last birthday were enrolled in the program. Informed consent from the patients' guardians (or from the patients themselves if at least 18 years old) was obtained upon entry into the program. Personal information, primary diagnosis, entry and followup clinical data, attendance to Lipat Kalinga activities including visits to the Adolescent Renal Transition Clinic (ARTC), and relevant multidisciplinary notes were logged in individual patient files. Children residing outside of NCR and with no consent were excluded from participation in the transition program. All patients went through the phases of Lipat Kalinga and were evaluated periodically. Based on both patient and Core Transition Team feedbacks, positive learning was reinforced while gaps were addressed correspondingly through one-on-one sessions/catch-up modules.

\section{Results}

\section{Description of the PGH Transition Program (Lipat Kalinga)}

Lipat Kalinga is a structured hospital-based model meant to make the transition from the care of pediatric to adult nephrology a seamless, gradual and planned process. The 
pediatric and adult nephrology services are the primary coordinators and are supported by a multidisciplinary Core Transition Team composed of subspecialists from the Department of Internal Medicine and the Department of Pediatrics (Section of Adolescent Medicine), social workers, nutritionists, nurses, teachers, and mental health specialists. Lipat Kalinga has four phases.

\section{Phase I: Preparation}

Teens are educated about their chronic condition, particularly on understanding their disease and its treatment. They are provided with an action plan upon recognizing signs and symptoms of deterioration. They are taught skills in self-management i.e. making an appointment to the doctor's medical clinic by themselves, taking responsibility for medications, and seeking help when needed. They are oriented about the entire transition process, including attendance to the ARTC held every fourth Friday of the month and to joint pediatric adult nephrology clinics and multidisciplinary conferences. Table 3 shows the schedule of activities for 2010.

Table 3. Schedule of Annual Lipat Kalinga Activities (January to December 2010)

\begin{tabular}{|c|c|c|}
\hline Session & Activity & Responsible Group \\
\hline 1 & $\begin{array}{l}\text { Getting to know you; introduction } \\
\text { to program }\end{array}$ & Team members \\
\hline 2 & $\begin{array}{l}\text { My life line (Speaker: Adult CKD } \\
\text { patient) }\end{array}$ & $\begin{array}{l}\text { Medical Social Service } \\
\text { Adolescent Service }\end{array}$ \\
\hline 3 & $\begin{array}{l}\text { Summer Camp } \\
\text { (Topic: Becoming a Teenager; Boy- } \\
\text { Girl relationships) } \\
\text { *TRANSITION/GRADUATION }\end{array}$ & $\begin{array}{l}\text { Team members } \\
\text { Patients }\end{array}$ \\
\hline 4 & $\begin{array}{l}\text { Renal Anatomy and Physiology: } \\
\text { How disease affects various } \\
\text { functions, growth \& development }\end{array}$ & Pediatric Nephrology \\
\hline 5 & $\begin{array}{l}\text { Taking care of myself (loving your } \\
\text { kidneys) }\end{array}$ & Pediatric Nephrology \\
\hline 6 & $\begin{array}{l}\text { Taking care of myself (healthy } \\
\text { lifestyle) }\end{array}$ & $\begin{array}{l}\text { Adult Nephrology } \\
\text { Team members }\end{array}$ \\
\hline 7 & Nutrition & Dietary service \\
\hline 8 & $\begin{array}{l}\text { KAYA KO! Communication skills; } \\
\text { How to talk to parents, doctors and } \\
\text { other adults }\end{array}$ & $\begin{array}{l}\text { Medical Social Service } \\
\text { Adolescent Service }\end{array}$ \\
\hline 9 & $\begin{array}{l}\text { KAYA KO! Being responsible for } \\
\text { my own healthcare } \\
\text { *TRANSITION/GRADUATION }\end{array}$ & $\begin{array}{l}\text { Medical Social Service } \\
\text { Adolescent Service } \\
\text { Pediatric Nephrology } \\
\text { Team members }\end{array}$ \\
\hline 10 & $\begin{array}{l}\text { ANG GALING KO! We've Got } \\
\text { Talent }\end{array}$ & $\begin{array}{l}\text { Medical Social Service } \\
\text { Adolescent Service }\end{array}$ \\
\hline 11 & $\begin{array}{l}\text { Transitioning with the Adult } \\
\text { Nephrologist }\end{array}$ & Adult Nephrology \\
\hline 12 & Christmas Celebration & $\begin{array}{l}\text { Team members } \\
\text { Patients and Parents }\end{array}$ \\
\hline
\end{tabular}

Phase II: Assessment of readiness

An Active Transition Checklist for 16-18 year olds (Figure 1) [with permission from Sue Towns] provides the formal criteria for readiness for transfer as determined by the Core Transition Team. A Filipino version of the UNC Transition Readiness Survey ${ }^{11}$ directly translated into Tagalog, the Philippine national language (with permission from Maria Ferris, et al), was made available to and was filled up by the patients as a feedback form. The survey contained 33 questions in 10 major domains that evaluated knowledge and skills characteristic of adult-oriented health care (Appendix). Answers were appropriately scored as affirmative/present (1.0), plus-minus (0.5) or negative/absent (0.0). Around transfer time, the total score should be perfect/near perfect. At least $75 \%$ participation in modules/conferences and visits to the ARTC was considered reasonable compliance with transition activities. The Pediatric Nephrology staff recorded these via an attendance sheet prepared for this purpose.

\section{Active Transition Checklist*}

1. Attend Adolescent Renal Transition Clinic

2. Attend group program

3. Self Management Scale Review 6-monthly

4. Written Information on Adult Services

5. Adult services discussed

6. Joint Paediatric / Adult Consultant Meeting

7. Adult Services Visit

8. Appointment made by Nurse for Transition

9. Transition referral letter sent

10. First appointment attended

11. Successful Transition feedback from

Young person

Adult service

Figure 1. Active Transition Checklist

* With permission from Sue Towns, Children's Hospital at Westmead, NSW, Australia

Phase III: Physical transfer

The transfer coordinator from Pediatric Nephrology endorses the patient's personal file, case summary and Active Transition Checklist to the transfer coordinator from Adult Nephrology. Physical transfer is implemented between ages 18 and 19 years. Formal graduation/endorsement programs are held twice a year where transition graduates provide testimonials.

Phase IV: Post-transfer follow-up

The transfer coordinator from Adult Nephrology facilitates the post-transfer visit by the pediatric team.

Figure 2 (modified with permission from Sue Towns) shows the Transition Map designed for Lipat Kalinga. Any 
patient between the ages of 10 and 18 years diagnosed as having CKD or Non-CKD illness was deemed eligible for inclusion into the study. He was further evaluated at the ARTC where he was categorized by age at entry as belonging to the Orientation Group (10-12 years old), Preparation Group (13-15 years old), and Active Transition Group (16-18 years old). Transfer to the Adult Renal Clinic occurred at age 18-19 years; further on, post-transfer visits by the pediatric team were undertaken.

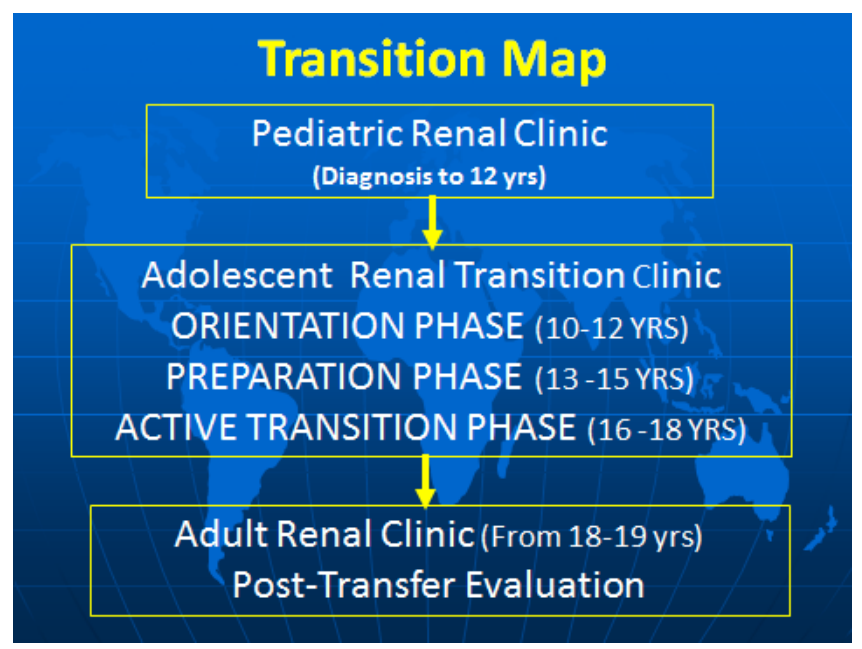

Figure 2. Transition Map used in Lipat Kalinga (Modified, with permission, from Sue Towns, Children's Hospital at Westmead, NSW, Australia)

\section{Patients enrolled in the Program}

Of the 95 patients from NCR, only 51 patients were enrolled in the program. The 44 patients were dropped because they were lost to follow up. The breakdown of patients include 17 with Chronic Kidney Disease (CKD) and 34 with non-CKD illnesses. Table 4 presents the characteristics of the CKD and non-CKD groups. There were more boys in the CKD group. Non-CKD patients were younger at the time of diagnosis and also younger at entry into Lipat Kalinga. Successful transfer to Adult Nephrology was done between 9 and 34 months from entry into the program in 12 subjects - 8 from the CKD and 4 from the nonCKD group. Still in the pre-transfer stage were 28 non-CKD and 6 CKD patients. Before they could be transferred, 3 CKD and 2 Non-CKD patients died and could not complete the program.

Majority of CKD patients were in Stage 5 (severe disease/end-stage renal disease [ESRD], glomerular filtration rate of $\left.<15 \mathrm{ml} / \mathrm{min} / 1.73 \mathrm{~m}^{2}\right)$ secondary to chronic glomerulonephritis (CGN) and reflux nephropathy (RN) (14 of $17,82.3 \%)$. Non-CKD illnesses were principally attributed to nephrotic syndrome (NS) (15 cases, 44.1\%), mostly steroid-dependent disease; lupus nephropathy (LN) (10 cases, 29.4\%), mostly un-biopsied clinical lupus and Class IV or diffuse glomerulonephritis; and tubulopathy (8 cases, 23.5\%), mostly distal tubular acidosis (dRTA) and potassium-losing disease (Table 5).

Table 4. General Data of Patients admitted to Lipat Kalinga

\begin{tabular}{lll}
\hline \multicolumn{1}{c}{ Patient Characteristics } & CKD (n=17) & Non-CKD (n=34) \\
\hline Male: number (\%) & $12(70.8 \%)$ & $18(53.0 \%)$ \\
Age at diagnosis, mean (SD) & $14.4(3.25)$ & $12.8(2.56)$ \\
Age at entry, mean (SD) & $16.3(1.78)$ & $14.4(2.32)$ \\
No. of patients transferred (\%) & $8(47.0 \%)$ & $4(11.8 \%)$ \\
No. of patients in pre-transfer stage & $6(35.3 \%)$ & $28(82.4 \%)$ \\
Mortality pre-transfer (\%) & $3(17.6 \%)$ & $2(5.9 \%)$ \\
\hline Legend: CKD = chronic kidney disease; Non-CKD = lupus nephropathy; nephrotic \\
syndrome; tubulopathy; Takayasu disease
\end{tabular}

Table 5. Etiologies of CKD and Non-CKD among patients in Lipat Kalinga

\begin{tabular}{|c|c|c|c|}
\hline CKD & & Non-CKD: No. (\%) & \\
\hline Chronic glom & phritis & Lupus nephropathy & $10(29.4)$ \\
\hline In Stage 5 & $12(70.6)$ & Biopsied, Class IV & $3(30.0)$ \\
\hline In Stage 4 & $1(5.9)$ & III & $1(10.0)$ \\
\hline Reflux nephrc & & II & $1(10.0)$ \\
\hline In Stage 5 & $2(11.8)$ & Unbiopsied, Clinical lupus & $5(50.0)$ \\
\hline Juvenile gout & & Nephrotic syndrome & $15(44.1)$ \\
\hline In Stage 5 & $1(5.9)$ & Biopsied, FGS & $1(6.7)$ \\
\hline Distal renal tu & cidosis & Unbiopsied, & \\
\hline In Stage 3 & $1(5.9)$ & Steroid-dependent & $13(86.7)$ \\
\hline & & Steroid-resistant & $1(6.7)$ \\
\hline & & Tubulopathy & $8(23.5)$ \\
\hline & & Distal renal tubular acidosis & s $4(50.0)$ \\
\hline & & $\mathrm{K}+-$ losing & $3(37.5)$ \\
\hline & & Gitelman's syndrome & $1(12.5)$ \\
\hline & & Takayasu disease & $1(2.9)$ \\
\hline Total & 17 & Total & 34 \\
\hline
\end{tabular}

Legend: $\mathrm{ml} / \mathrm{min} / 1.73 \mathrm{~m}^{2} ;$ Stage $3=$ GFR 30-59 $\mathrm{ml} / \mathrm{min} / 1.73 \mathrm{~m}^{2}$. Non-CKD: LN Class IV = diffuse proliferative glomerulonephritis $(G N)$; Class III = focal proliferative GN; Class $I I=$ mesangial proliferative $G N ; \quad N S, F G S=$ focal glomerular sclerosis

Post-transfer, all 4 non-CKD patients (2 LN, 1 NS, 1 tubulopathy) were well and regularly following up at the Adult Renal and allied clinics. Among the 8 CKD patients who were transferred, one (now age 22 years) had a kidney transplant, 2 (now age 20 and 21 years) remained on hemodialysis, and 5 expired or were lost to follow-up within a 6-7 month period from transfer. There was positive feedback from the 7 patients who survived (transition readiness) and from the Core Transition Team (attendance to transition activities and ARTC visits) around transfer time were consistently noted.

Three CKD patients (all in Stage 5/ESRD, aged 15-16 years) and 2 patients with severe LN (also aged 15 and 16 years) died before they could finish the program. Deaths were due to poor disease control or overwhelming sepsis. All 5 deaths registered poor (less than $50 \%$ ) attendance to the transition modules and erratic visits to the ARTC. 
Thirty-four (34) patients remained at the Pre-Transfer Stage (Table 6): 11 patients aged 16-18 years at entry were being actively transitioned (Active Transition Group), 15 cases aged 13-15 years were being prepared (Preparation Group), and 8 cases aged 10-12 years were being oriented (Orientation Group). All 11 patients in the Active Transition Group - 3 who had CKD (mean follow-up duration, 10.3 months), and 8 who had Non-CKD illness (mean follow-up duration, 7.5 months) - completed at least $75 \%$ of consults at the ARTC and of transitioning activities (with catch-up modules for 3 patients aged 16-17 years who had been seen for 9 months). All had positive feedback using the Core Transition Team's evaluation and the patient-accomplished Transition Readiness Survey.

Also, 11 out of 15 patients (73.3\%) with Non-CKD illness in the Preparation Group substantially complied with program requirements after a mean follow-up period of 24.0 months. The same was observed among 5 out of 8 Non-CKD patients (62.5\%) and one out of 8 CKD patients (12.5\%) in the Orientation Group after a mean follow-up period of 19.6 and 15.0 months, respectively.

In this report, the possible impact of Lipat Kalinga on disease control and adolescent quality of life was not assessed.

\section{Discussion}

In a position paper of the Society for Adolescent Medicine, Blum, et al defined transition as a purposeful, planned process that addresses the medical, psychosocial and educational/vocational needs of adolescents with chronic physical and medical conditions as they move from child-centered to adult health care systems. ${ }^{5}$ In contrast, transfer is the mere movement to a new health care facility and/or provider, and therefore just an arbitrary, irregular event where the care is shifted by referral information only. ${ }^{7}$ As self-management and independence are major characteristics of adult health care, and adult units differ from their pediatric counterparts in so many ways, consensus statements and formal guidelines focused on health care transitions (HCTs) for adolescents and young adults with a variety of special health care needs have been published. , $12-15^{-15}$

Pediatric CKD and ESRD are examples of illnesses needing special health care and HCT not only because disease management is complicated but also because these illnesses occur at a critical time in the growing child's physical, mental and psychosocial development. Reports by Ferris and Mahan and by other investigators underscored the need for a structured program that involves patients, families, pediatric and adult health care providers and interdisciplinary coordination to help effect successful transfer. $8,12,16$ Furthermore, it is recommended that the transition process for each adolescent or young adult be individualized, especially as regards timing of transfer to adult health services.3,4,8 However, even in the aforementioned renal centers with well-established HCT programs, they still grappled with non-compliance to treatment, non-adherence to program schedules and other problems. ${ }^{12}$

The Lipat Kalinga transition model involved a full-year calendar of multidisciplinary activities that were faithfully coordinated by a Core Transition Team. The four phases of Lipat Kalinga (preparation, assessment of readiness, physical transfer, and post-transfer follow-up) carried the key ingredients of a well-oiled structured transition program espoused by HCT advocates. These included patient education on disease management and related issues, skills development/enhancement, peer relationships, introduction to transition and independence going to the adult health care units, actual readiness for physical transfer, joint clinics of the pediatric and adult nephrology staff with or without the participation of the rest of the multidisciplinary group, and post-transfer observations. ${ }^{14}$

Lipat Kalinga introduced several innovations and interventions: (1) presence of a dedicated ARTC which was essential in catering to specific medical, psychosocial and other needs of patients in the program [operations every fourth Friday of the month from June 2008]; (2) assessment for readiness for transfer via the Filipino version of the Transition Survey (a culturally-appropriate patient feedback

Table 6. Latest status of 34 Patients at the Pre-Transfer Stage

\begin{tabular}{|c|c|c|c|}
\hline & $\begin{array}{c}\text { Active Transition Group, } \\
\text { 16-18 years old } \\
(\mathrm{n}=11)\end{array}$ & $\begin{array}{c}\text { Preparation Group, } \\
\text { 13-15 years old } \\
(n=15)\end{array}$ & $\begin{array}{c}\text { Orientation Group, } \\
\text { 10-12 years old } \\
(n=8)\end{array}$ \\
\hline \multicolumn{4}{|l|}{ CKD $(n, 6)$} \\
\hline Duration of ff-up, months & 9-11 (mean, 10.3) & 6-8 (mean, 7.0) & 15 \\
\hline \multicolumn{4}{|c|}{ Attendance to modules/clinics } \\
\hline $75-100 \%$ & $3 / 11(27.3 \%)$ & --- & $1 / 8(12.5 \%)$ \\
\hline$<75 \%$ & -- & $2 / 15(13.3 \%)$ & -- \\
\hline \multicolumn{4}{|l|}{ Non-CKD $(n, 28)$} \\
\hline Duration of ff-up, months & 4-11 (mean, 7.5) & 7-33 (mean, 24.0) & 3-33 (mean, 19.6) \\
\hline \multicolumn{4}{|c|}{ Attendance to modules/clinics } \\
\hline $75-100 \%$ & $8 / 11(72.7 \%)$ & $11 / 15(73.3 \%)$ & $5 / 8(62.5 \%)$ \\
\hline$<75 \%$ & -- & $2 / 15(13.3 \%)$ & $2 / 8(25.0 \%)$ \\
\hline
\end{tabular}


tool) and at least $75 \%$ attendance to transition modules and visits to the ARTC (a healthcare provider-driven evaluation); and (3) holding of formal graduation/endorsement ceremonies to showcase a celebratory mood during the actual physical transfer from pediatric to adult health care, featuring the testimonies of transition graduates as role models.

Unlike other studies that involved only patients having CKD Stage 4 (severe decrease in glomerular filtration rate, $\left.15-29 \mathrm{ml} / \mathrm{min} / 1.73 \mathrm{M}^{2}\right)$ to Stage $5\left(\mathrm{ESRD},<15 \mathrm{ml} / \mathrm{min} / 1.73 \mathrm{M}^{2}\right.$ ) in highly-specialized units, the proponents wanted to expand the patient base to include non-CKD conditions. The management of these non-CKD conditions was not as complicated as that of CKD but still carried the potential for chronicity with or without deterioration of kidney function, and thus would likely benefit as much from Lipat Kalinga activities. ${ }^{8}$ The 34 non-CKD illnesses involved in this study (LN, NS, tubulopathy, Takayasu disease) could be diagnosed at early adolescence as demonstrated herein and could last for long periods of time as is already widely known.

In this study, 12 patients (23.5\%) --- 8 CKD, 2 LN, 1 NS and 1 tubulopathy --- were successfully transferred to adult health care. All 4 non-CKD and 3 of the 8 CKD patients were well at last follow-up accounting for a $58 \%$ overall survival rate. Very good patient and Core Transition Team feedbacks around transfer time and at latest follow-up were consistently noted. These suggested that Lipat Kalinga contributed to a satisfactory clinical outcome.

Unfortunately, five patients ( 3 with CKD 5/ESRD aged 15-16 years and 2 with severe lupus nephritis also aged 15 and 16 years) died from poor disease control, cardiovascular complications and severe sepsis before they could complete their program. Parekh, et al reported that, among 15-19 year olds, cardiovascular event rates were nearly 1,000-fold greater with ESRD when compared with age-matched peers from the general population. ${ }^{17}$ Severe sepsis was a major cause of mortality and morbidity among these PGH patients with nosocomial infection rates for 2008, 2009, 2010 and 2011 reached 18\%, 24\%, 19\%, and 13\%, respectively (Personal communication, Infectious and Tropical Disease Section, Department of Pediatrics, June 2012).

Five of $8 \mathrm{CKD}$ patients died or were lost to follow-up within 6-7 months post-transfer from reasons beyond the Team's control. Problems were usually related to the huge financial burden associated with treating severe ESRD even in developed countries. ${ }^{18}$ It is expected to be more difficult in developing countries like those in Southeast Asia and with a group as socio-economically challenged as those included in this study. ${ }^{19,20}$

Of the 34 patients who remained in the study pretransfer list, 11 were in the Active Transition Group (16-18 years old) awaiting their graduation --- 8 with non-CKD and 3 with CKD illness. All completed at least $75 \%$ of transitioning activities and required consults at the ARTC. All gave very positive feedbacks on transition readiness. It appears that the patients would be readier for transfer and for post-transfer monitoring as compared with the first 12 patients, and should be assessed in the future as to the efficacy of their program using evidence-based transition tools, such as STARx (successful transition to adulthood with treatment $[\mathrm{Rx}]),{ }^{7}$ the UNC TRxANSITION Scale, ${ }^{11}$ and the Transition Readiness Assessment Questionnaire (TRAQ). ${ }^{21}$ Statistically significant improvements in health outcomes post-transition (mostly among diabetic patients) have been reported in a recent systematic review. ${ }^{22}$ Some transition programs have apparently benefited children with other diseases in terms of improved follow-up, disease control and quality of life. ${ }^{23,24,25}$ We noted the $\geq 75 \%$ compliance rate not only of all 11 CKD and Non-CKD adolescents in the Active Transition Group but as well of most of the Non-CKD adolescents under the Preparation and Orientation Groups. Their subsequent feedbacks in a follow-up status report will give us an idea as to what ageand development-appropriate modules can be used at various entry levels, as brain development is known to continue until age 25 years. ${ }^{26}$ Furthermore, it will be interesting to generate recommendations on what other transition program attributes can be culturally-unique for the Filipino adolescent with chronic kidney and urinary tract disease moving towards adult health services.

The wide spectrum of pediatric kidney and urinary tract diseases surviving beyond 19 years of age now includes those that internists and adult nephrologists have not had considerable training in (e.g., congenital anomalies of the kidney and urinary tract). Several internists articulated the need for more experience in these areas. ${ }^{27,28}$ This experience gap adds more reason for the ISN- and IPNA-initiated consensus call ${ }^{3,4}$ for regional societies to develop programs (training, service or both) that are relevant to the advancement of transitioning models and possible inclusion of appropriate modules in residency and post-residency nephrology fellowship programs.

\section{Limitations}

Program impacts on disease control or quality of life were not assessed.

\section{Conclusion and Recommendation}

Lipat Kalinga is a systematic program for transitioning patients with chronic illnesses from the pediatric clinic to the adult clinic. We recommend that Lipat Kalinga be replicated in hospitals with multidisciplinary capabilities. Its supplemental contribution to the holistic care of adolescents afflicted with chronic kidney illnesses at a crucial time of their development is relevant and timely.

We need more local and prospective data on similarlystructured transitioning programs, particularly those 
focused on uniqueness and long-term benefits among adolescents with prolonged and debilitating kidney/urinary tract diseases.

\section{Acknowledgments}

The authors thank all the pediatric and adult post-residency fellows and residents involved in the Lipat Kalinga 2008-2011 activities (especially Drs. Noel S. Montes, James Robertson C. Pichel and Bryan M. Flores), Dr. Jimmy P. Dumlao II for technical assistance and most of all the Alfiler family.

\section{References}

1. Cameron JS. The continued care of children with renal disease into adult life. Pediatr Nephrol. 2001; 16(8):680-5.

2. Cameron JS. The continued care of pediatric patients with renal disease into adult life. Am J Kidney Dis. 1985; 6(2):91-5.

3. Watson AR, Harden P, Ferris M, Kerr PG, Mahan J, Ramzy MF. Transition from pediatric to adult renal services: a consensus statement by the International Society of Nephrology (ISN) and the International Pediatric Nephrology Association (IPNA). Kidney Int. 2011; 80(7):704-7.

4. Watson AR, Harden P, Ferris M, Kerr PG, Mahan J, Ramzy MF. Transition from pediatric to adult renal services: a consensus statement by the International Society of Nephrology (ISN) and the International Pediatric Nephrology Association (IPNA). Pediatr Nephrol. 2011; 26(10):1753-7.

5. Blum RW, Garell D, Hodgman $\mathrm{CH}$, et al. Transition from child-centered to adult health-care systems for adolescents with chronic conditions: a position paper of the Society for Adolescent Medicine. J Adolesc Health. 1993; 14(7):570-6.

6. American Academy of Pediatrics, American Academy of Family Physicians, American College of Physicians - American Society of Internal Medicine. A consensus statement on health care transitions for young adults with special health care needs. Pediatrics. 2002; 110 (6 Pt 2):1304-6.

7. Warady BA, Ferris M. The transition from pediatric to adult-centered health care. Nephrol News Issues. 2009; 23(10):49-51.

8. Watson AR, Warady BA. Transition from pediatric to adult-centered care. Dial Transplant. 2011; 40(4):156-8.

9. Bennett DL, Towns SJ, Steinbeck KS. Smoothing the transition to adult care. Med J Aust. 2005; 182(8):373-4

10. Ferris ME, Gipson DS, Kimmel PL, Eggers PW. Trends in treatment and outcomes of survival of adolescents initiating end-stage renal disease care in the United States of America. Pediatr Nephrol. 2006; 21(7):1020-6.

11. Ferris ME, Harward DH, Bickford $\mathrm{K}$, et al. A clinical tool to measure the components of health-care transition from pediatric care to adult care: The UNC TR(x)ANSITION Scale. Ren Fail. 2012; 34(6):744-53.

12. Watson AR. Problems and pitfalls of transition from paediatric to adult renal care. Pediatr Nephrol. 2005; 20(2):113-7.

13. American Academy of Pediatrics Committee on Children with Disabilities and Committee on Adolescence (AAP). Transition of care provided for adolescents with special health care needs. Pediatrics. 1996; 98(6 Pt 1):1203-6.

14. Rosen DS, Blum RW, Britto M, Sawyer SM, Siegel DM; Society for Adolescent Medicine. Transition to adult health care for adolescents and young adults with chronic conditions: position paper of the Society for Adolescent Medicine. J Adolesc Health. 2003; 33(4):309-11.

15. Adolescent Health Committee, Canadian Paediatric Society (CPS). Transition to adult care for youth with special health care needs. Paediatr Child Health. 2007; 12(9):785-88.

16. Ferris ME, Mahan JD. Pediatric chronic kidney disease and the process of health care transition. Semin Nephrol. 2009; 29(4):435-44.

17. Parekh R, Smoyer WE, Milne JL, et al. Letter from the authors of "Improved Growth in Young Children with Severe Chronic Renal Insufficiency Who Use Specified Nutritional Therapy" which appeared on pages 2418-2426 of the November 2001 issue of JASN. J Am Soc Nephrol. 2002; 13(5):1421-2.

18. Collins AJ, Foley RN, Chavers B, et al. United States Renal Data System (USRDS) 2011 Annual Data Report: Atlas of Chronic Kidney Disease and EndStage Renal Disease in the United States. Am J Kidney Dis. 2012; 59(1 Suppl 1): A7.

19. Jha V. Current status of chronic kidney disease care in Southeast Asia. Semin Nephrol. 2009; 29(5):487-96.
20. Philippine Society of Nephrology. Chronic kidney disease. The Philippine situation. In: NNHeS 2003-2004 Renal Report. National Nutrition and Health Survey [Online]. [cited 2012 July]. Available from http://www.slideserv.com.pcp.org.ph/HERO/chronic kidney disease (PSN).

21. Sawicki GS, Lukens-Bull K, Yin X, et al. Measuring the transition readiness of youth with special health care needs: validation of the TRAQ - Transition Readiness Assessment Questionnaire. J Pediatr Psychol. 2011; 36(2):160-71.

22. Crowley R, Wolfe I, Lock K, McKee M. Improving the transition between paediatric and adult healthcare: a systematic review. Arch Dis Child. 2011; 96(6):548-53.

23. McDonagh JE, Southwood TR, Shaw KL; British Society of Paediatric and Adolescent Rheumatology. The impact of a coordinated transitional care programme on adolescents with juvenile idiopathic arthritis. Rheumatology (Oxford). 2007; 46(1):161-8

24. Sawyer SM, Collins N, Bryan D, Brown D, Hope MA, Bowes G. Young people with spina bifida: transfer from paediatric to adult health care. J Paediatr Child Health. 1998; 34(5):414-7.

25. Nasr SZ, Campbell C, Howatt W. Transition program from pediatric to adult care for cystic fibrosis patients. J Adolesc Health. 1992; 13(8):682-5.

26. Giedd JN. The teen brain: insights from neuroimaging. J Adolesc Health. 2008; 42(4):335-43.

27. Peter NG, Forke CM, Ginsburg KR, Schwarz DF. Transition from pediatric to adult care: internists' perspectives. Pediatrics. 2009; 123(2):417-23.

28. Patel MS, O'Hare K. Residency training in transition of youth with childhoodonset chronic disease. Pediatrics. 2010; 126Suppl 3:S190-3.

\section{Appendix}

Transition Readiness Survey* (Filipino Version)**

1. Knowledge about chronic kidney condition (Pangalan ng sakit, sintomas, epekto sa kalusugan)

2. Knowledge about treatment (Mga gamot, oras ng pag-inom, para saan, masamang epekto kung itigil)

3. Ability to follow instructions (Kayang sumunod sa mga bilin, pupunta sa doctor/clinic sa takdang araw ng konsulta)

4. Knowledge about nutrition (Ano ang "special diet", mga halimbawa ng dapat kainin, pagbasa ng "nutrition label")

5. Self-management skills (Sariling pag-inom ng gamot, pagpunta sa botika, pagtawag sa doctor kung may kailangan, pagpunta sa Emergency Room kung mabigat ang pakiramdam)

6. Knowledge of reproductive health (Pagbubuntis, mga bagay tungkol sa sex, pag-alaga sa sarili habang nakikipagtalik)

7. School/vocation (Mga plano tungkol sa pag-aaral at pag-trabaho)

8. Health insurance (Kung meron ngayon, paano kumuha ng segurong pangkalusugan sa takdang panahon)

9. Continuing support (Sino ang mga magpaalala sa mga bagay pangkalusugan pagdating sa hustong gulang)

10. New health providers (Paghanap ng bagong doctor/clinic kung kailangan, paglipat ng medical records)

*Directly translated into Tagalog, with permission from Ferris, et al ** The Filipino Version has 33 questions in 10 domains. Yes/present answers were scored (1.0), plus-minus answers (0.5), and no/absent 


\section{Patient Information Brochure}

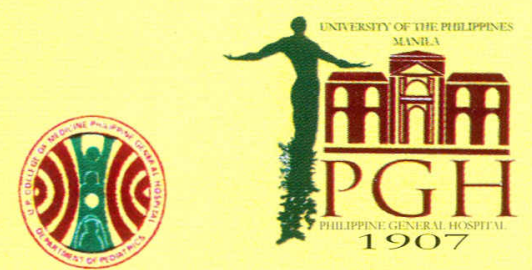

A joint program of the Department of Pediatrics and the Department of Medicine

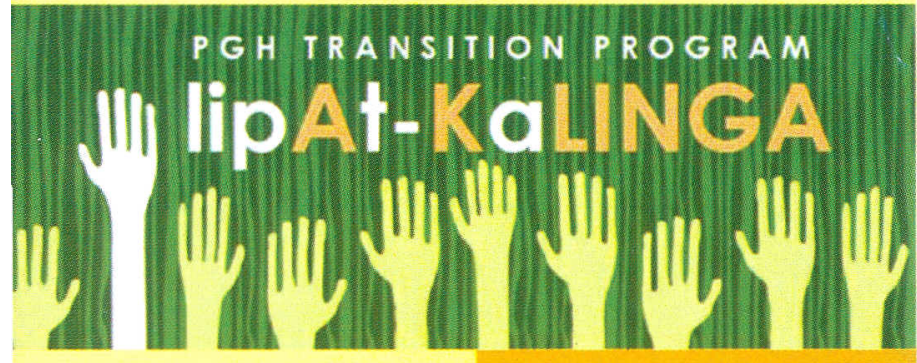

jscIs:jijioss program for

\section{teens}

\section{Lipat- move/transition} -Kalinga nurture/care

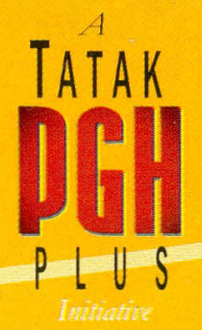

